\title{
Discussion on the Development Strategy of Agricultural Business Based on "Internet Plus"
}

\author{
Yan Xu \\ Department of Management, Yango University, Fuzhou City, Fujian Province, China \\ 181391620@qq.com
}

Keywords: Internet plus; agricultural business; development strategy

\begin{abstract}
Internet plus" has brought new opportunities for the development of Chinese economy. In rural areas, the agricultural e-commerce is the best way to combine "Internet plus" and traditional agriculture. Through the Internet, the agricultural e-commerce has become the channel between rural markets and urban markets, and brought more and more career opportunities in rural areas so as to promote the inflow of funds from cities to rural areas. This paper analyzes the current situation of Chinese agricultural business development and several problems in accordance with the upsurge of agricultural e-commerce based on "Internet plus", summarizes several agricultural e-commerce modes, analyzes their main advantages and disadvantages, and eventually provides some prospectives and corresponding strategies to agricultural e-commerce.
\end{abstract}

\section{Introduction}

With the development of the Internet economy, there is an upsurge of e-commerce all over the world. At the same time, agriculture also begins to get involved in the Internet and eagers to catch up with the trend of "Internet plus" (Fan, 2014). The agricultural e-commerce is a new mode of agricultural development, which evolves from the traditional agriculture, and becomes an accelerator of the agricultural economic development (Yongjin, 2013). However, there are still several obstacles during the development of the agricultural e-commerce, due to the problems in techniques, logistics and qualities. Therefore, it is essential for governments, enterprises and farmers to work together to utilize relevant policies and strategies, by which the agricultural e-commerce obtains a safe and sound development (Lianjun, 2015).

The agricultural e-commerce has a broad development space and a huge development potential, based on which the agricultural e-commerce not only promote the dissemination of information so as to realize the development of agricultures, increase the transparency of agricultural market and achieve a reasonable market price, but also expand production and operation, achieve targeted productions gradually. In addition, the agricultural e-commerce improves the competitiveness of agriculture products so as to perfect the industrial structure of agriculture in China (Liguo, 2016). Therefore, it is necessary to adopt reasonable modes and strategies based on "Internet plus" to promote the development of agricultural e-commerce.

\section{Agricultural E-commerce Based on "Internet plus"}

"Internet plus" refers to a set of information technology (including mobile Internet, cloud computing, big data technology and etc.) in economic activities, which is similar to Information Superhighway and Industry 4.0. "Internet plus" was proposed by China's prime minister Li Keqiang in his Government Work Report on March 5, 2015 so as to keep pace with the Information Trend. It is a new economic model, using innovative achievements based on Internet technologies, to integrate all aspects in the economic society, enhance the development and competitiveness of real economy and form a new situation of economic (Wencui, 2016).

The agricultural e-commerce includes a series of trading activities centered on agricultural production and operation, involving the agricultural production management, the online sales, the 
online payment and the logistics configuration and management. With the promotion of "Internet plus”, governments, enterprises and farmers have paid more and more attention to the agricultural e-commerce, and then issued a series of e-commerce regulations to promote the development of agricultural e-commerce. Based on the above economic and technical environment, the agricultural e-commerce has been provided a series of economic and policy supports. Although there are still many urgent problems to be solved and improved, the development trend of the agricultural e-commerce is still impressive.

\section{The Situation of Agricultural E-commerce}

To date, the agricultural e-commerce has experienced a continuous rise and elimination. Thus, the modes of agricultural e-commerce are becoming more and more solidified, and show a variety of characteristics gradually. The paper analyzed several modes of agricultural e-commerce. Although the increase of agricultural e-commerce is slow, some corresponding results have been achieved based on "Internet plus".

In recent years, the central ministries and governments at all levels are working together to promote the construction of the agricultural e-commerce through the implementation of the central documents about "Internet plus". At the same time, the number of Internet user in China continues to increase, and the farmers' Internet awareness continues to strengthen. The above factors play important roles to the development of agricultural e-commerce, which shows a linear upward trend (as shown in Figure 1).

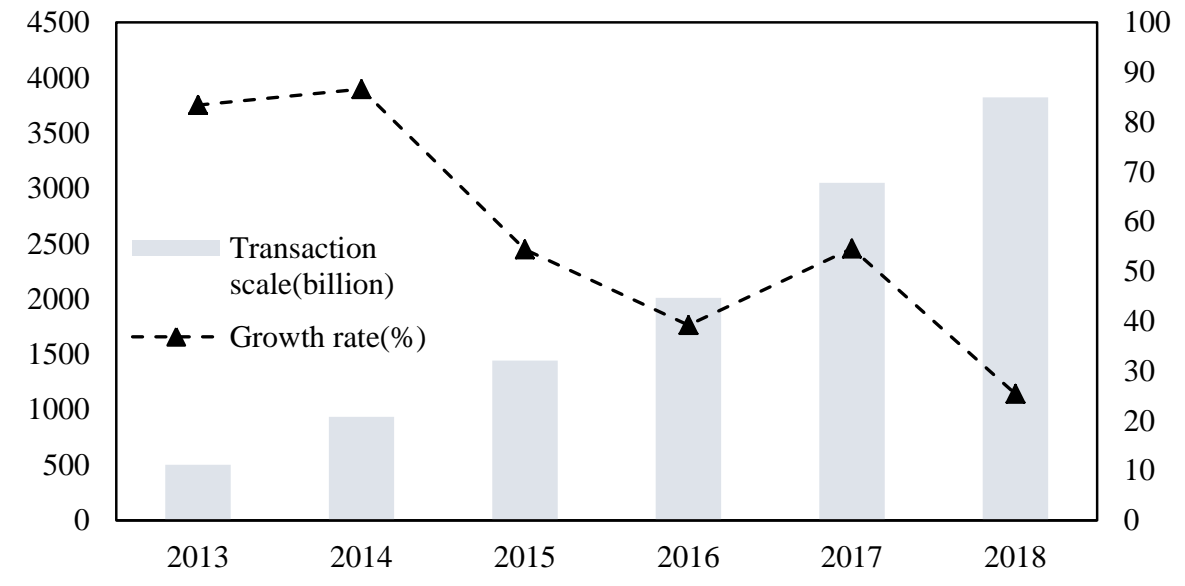

Figure 1 The transaction scale and growth rate of Chinese agricultural e-commerce form 2013 to 2018

In the recent "fifteen" period, Chinese agricultural information resources construction has achieved a great progress and achievement. In addition, the Ministry of Agriculture in China has set up more than 8000 information collection sites about agriculture throughout the country, and established more than 50 practical databases successively, such as the production, the market, the import and export of agricultural products, Furthermore, more and more large e-commerce platforms begin to utilize several approaches to promote the development of the agricultural e-commerce, such as Alibaba, SFBest and JD. Besides, with the development of "Internet plus", governments have paid more and more attention to the development of agriculture, and then increasingly more economic and political policies would tilt towards the agricultural e-commerce. What's more, the logistics cost is becoming an important constraint factor of agricultural e-commerce, when the traditional agricultural trading mode alternate to the agricultural e-commerce with the integration of various resources. In addition, there are still some problems in the establishment of the agricultural products market, logistics system and other aspects, which have hindered the development of Chinese agricultural e-commerce in varying degree. Therefore, when detecting the expectation and advantages, we should keep the sense of urgency, and utilize relevant 
approaches to solve these problems gradually.

\section{Mode of Agricultural E-commerce}

\subsection{Platform Modes}

The Alibaba platform is a multi-dimensional platform mode, and its subplatforms, such as Taobao, Tmall and Juhuasuan, are established based on multi-dimension. In addition, several innovative modes, such as the "picky eaters" platform and the "tongue of China", are appearing to provide online offering and origin pre-sale services with the development of cold-chain logistics. Figure 2 shows the transaction scale prediction through Alibaba.

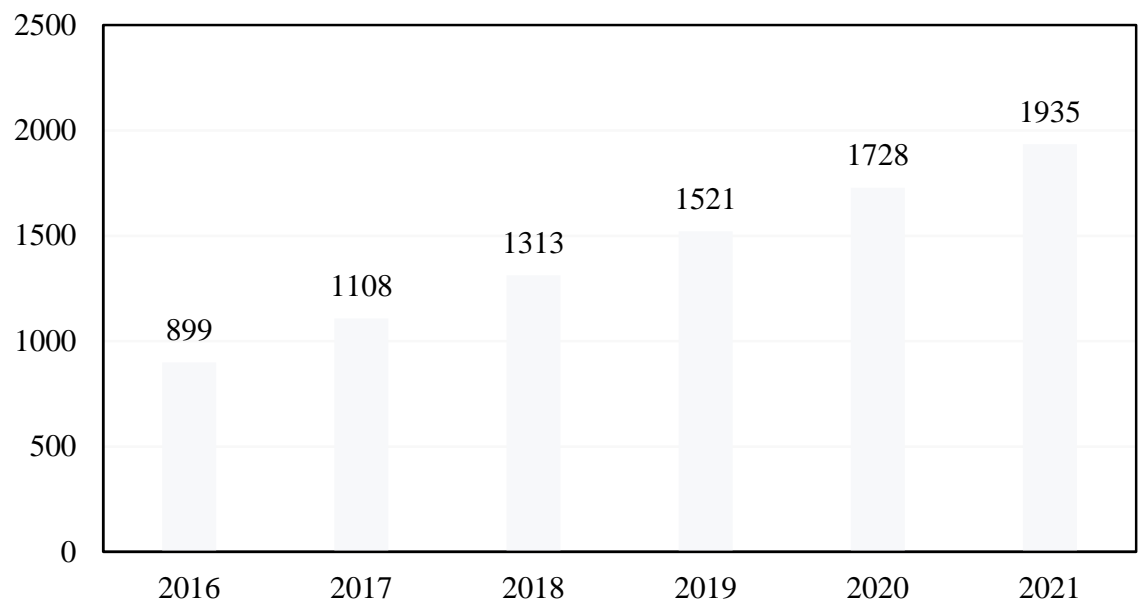

Figure 2 The transaction scale prediction of agricultural products through Alibaba

SFBest utilizes the high value-added category plus C2B direct supply platform mode. SFBest adopted independent operation mode in the early stage of its development, and the logistics sector is independent as well. The main characteristics of SFBest are high value-added products and lower logistics cost, which could reduce the operation risks. At last, SFBest has built a direct supply of agricultural products with a fast logistics service coupled with a direct supply chain seasonally.

JD utilizes transaction docking mode. JD is now only involve the online transaction of agricultural products based on open platform. In future, JD is also ready to integrate the purchase, storage transportation, marketing and after-sale services so as to provide quality certification and reputation insurance.

\subsection{Mode of Agriculture Base, Traditional B2C and Event Marketing}

This mode is one of the best choices for the small and medium agricultural e-commerce, which integrates agriculture base, unique B2C platform, event marketing strategy and customer experience together to form their unique operation modes. Although its operation scale is not large, it is undoubtedly an opportunity for small and medium agricultural e-commerce to provide high quality agricultural products. In addition, the experiential marketing strategy has attracted numerous cutomers.

\subsection{Mode of Localization plus $\mathrm{O} 2 \mathrm{O}$}

The Chongqing agricultural products group utilizes the localization mode, and integrates the distinctive characteristics of agricultural products. To date, many hypermarkets and supermarkets, such as WALMART, BBK and RT mart, have begun to frantically use the localization plus O2O mode.

\subsection{Online Auction Mode}

The Shouguang agricultural products wholesale market in Shandong Province has pioneered the online auction mode, and then other agricultural e-commerce are also conducting the online auction. 
Markets release relevant agricultural products and auction information in the Internet, and then the trade place and date are negotiated latter. After the transaction, the company receives the corresponding remunerations in proportion to sellers and buyers.

\section{The Development Strategy of Agricultural E-commerce based on “Internet plus”}

\subsection{Deepening the Construction of Financial System}

The perfect financial system ensures the benign development of e-commerce. It is essential to develop diversified rural financial system, improve network payment, credit construction and certification system and promote technological innovation, so as to form the the rural financial service system based on formal financial institutions, rural cooperative finance and government policies. In addition, modern payment approaches should be publicized and promoted in rural areas, such as non-cash payment, to promote financial institutions to countryside and provide convenient online banking services for villagers. Furthermore, capital investments should be increased, and relevant policies and financing channels should be established as well. At last, government should support financial enterprises to provide financial services to rural e-commerce enterprises and individuals, promote the deep integration of e-commerce and traditional agriculture and provide safe environment to rural e-commerce.

\subsection{Perfection the Transaction Platform of Agricultural E-commerce}

The e-commerce transaction platform is not only a window to publicize enterprises and commodities, but also timely release and update information, strengthen customer service, and promote the role of online transaction. The local government and enterprises should strengthen cooperation, and jointly build a agricultural e-commerce platform with information services, promotion, payment and logistics. In addition, government should actively cultivate rural e-commerce portal website, encourage small and medium enterprises to carry out e-commerce applications in the third party platform and explore innovative marketing modes, which are beneficial for establishing enterprises' image, reducing purchase cost and commodity inventory, and improving enterprises' competitiveness. Furthermore, the regulatory functions of agricultural e-commerce should be grasped to solve the rural market information asymmetry, price differences, lack of competition and other issues, to ensure market transparency. At last, governments and enterprises implement agricultural e-commerce expansion plan, establish a safe and sound consumption environment, in which way the agricultural e-commerce could be upgraded smoothly.

\subsection{Standardization of Agricultural Information Personnel}

With the development of agricultural e-commerce, agricultural information talents who are proficient in agricultural production, management and circulation, and master modern network information technology are urgently needed. At first, governments should improve the training of talents, strengthen the communication between school education and agricultural e-commerce market. At the same time, governments should work closely with universities and enterprises to cultivate high level "Internet plus" and agricultural e-commerce talents in the view of actual situations in various places. At last, a number of professionals willing to take root in agricultural e-commerce should be developed, which could promote the development of agricultural e-commerce, enhance the overall quality of agricultural information personnel.

\section{Conclusion}

To sum up, "Internet plus" has risen to national strategy. Due to the trend of combination between Internet industry and other industries, Chinese Internet has updated from consumer Internet to the Internet industry. In addition, the traditional agricultural industry chain might be alternated through the introduction of "Internet plus", such as informatization, networking technology and intelligentization. Furthermore, traditional agriculture can realize the alternation of new marketing strategy in production, operation, sale and other supporting aspects with the Internet technology 
applied to all aspects of agricultural management. At last, it is easy to improve the value and quality of agricultural products, overcome the drawbacks of traditional agriculture and alternate the traditional agriculture into an innovative "Internet agriculture".

\section{References}

[1] Fan, Liu, Minyu, Wang, 2014. Development Opportunity and Challenge of Fresh E-commerce in China, China Journal of Commerce. (12), pp.101-102.

[2] Wencui, Hu, 2016. Analysis on the Development of Fresh E-commerce O2O in China, China Journal of Commerce. (7), pp.34-35.

[3] Yongjin, Cai, 2013. Five Issues of Agricultural E-commerce Need to Pay Attention To, Market Modernization. (24), pp.12.

[4] Liguo, Xu, Meimei, Zhu, 2016. Research and Solution Of The Problem Of Cold Chain Logistics Of Fresh Agricultural Products In The Era Of Electricity Supplier, Jiangsu Commercial Forum. (4), pp.23-26.

[5] Lianjun, Yu, 2015. Research on the Development Model of Agricultural E-commerce Based on Internet plus, Agriculture Network Information. (11), pp.19-21. 